\title{
SISTEMA INTERAMERICANO DE PROTEÇÃO DE DIREITOS HUMANOS: UMA ANÁLISE A PARTIR DO CASO DAMIÃO XIMENES LOPES
}

Tatyana Scheila Friedrich ${ }^{1}$

\section{RESUMO}

O Sistema Interamericano de Direitos Humanos constitui-se numa importante ferramenta para garantir a salvaguarda dos direitos essenciais dos indivíduos por parte do Estado da OEA a que estão vinculados. Embora seja complementar à jurisdição interna, em função de circunstâncias políticas, econômicas e sociais do local, muitas vezes tal sistema se transforma na única esperança das vítimas para reaverem seus direitos. Foi o que aconteceu com os familiares de Damião Ximenes Lopes quando tiveram que recorrer à Comissão Interamericana, a qual, por sua vez, após os trâmites procedimentais, encaminhou o caso à Corte Interamericana. Esta, então, proferiu sentença responsabilizando o Brasil, nos termos reproduzidos neste artigo.

\section{INTRODUÇÃo}

O caso Damião Ximenes Lopes resultou na primeira sentença da Corte Interamericana relacionada ao Brasil, condenando-o a partir da verificação de sua responsabilidade na violação de determinados direitos humanos previsto na Convenção Americana.

Damião Ximenes Lopes, portador de transtorno mental e epilepsia, havia sido internado por sua mãe, Albertina Ximenes, na única clínica psiquiátrica da região da cidade de Sobral, no Ceará, no dia $1^{\circ}$ de outubro de 1999. Três dias depois, indignada, a mãe forçou a entrada na clínica pois havia foi informada por um funcionário que seu filho não tinha condições de receber visitas. Encontrou Damião com as mãos amarradas, passando muito mal,

\footnotetext{
${ }^{1}$ Doutora, Professora de Direito Internacional da UFPR e coordenadora do NDI
}

Revista Brasileira de Direito Internacional, Curitiba, v.3, n.3, jan./jun.2006 
sangrando e apresentando escoriações e hematomas, decorrentes de briga com os enfermeiros da Clínica. De volta para casa, recebeu a notícia de que seu filho havia morrido, por parada respiratória.

As denúncias feitas pela família ao Ministério Público, Polícia local e Comissão de Direitos Humanos da Assembléia Legislativa do Ceará, foram infrutíferas, o que a levou a buscar auxílio a órgão externo.

No cenário internacional da proteção dos direitos humanos existem, atualmente, dois grandes sistemas autônomos, com características próprias, que se diferenciam pelo âmbito de aplicação: sistema global e sistemas regionais.

Apesar de suas especificidades, os dois sistemas convivem de forma harmônica e coordenada, decorrente do objetivo comum que lhes são inerentes desde sua gênese: constituírem-se em mecanismos voltados à proteção dos direitos essenciais dos indivíduos sob sua jurisdição. "Estes mecanismos se complementam uns aos outros no desempenho de suas funções e na realização de seu propósito comum de assegurar uma proteção eficaz e cada vez mais extensa dos indivíduos lesados. O foco de atenção principal transferese assim da questão tradicional da delimitação de competências à do grau ou qualidade da proteção a ser estendida à pessoas vitimadas."

O caráter protetivo de seus instrumentos foi uma das reivindicações que impulsionaram o surgimento do ramo do direito consagrado pela doutrina como Direito Internacional do Direitos Humanos, que apareceu na metade do século XX como resposta e alternativa a toda a violência cometida contra os direitos humanos ao longo da Segunda Guerra Mundial.

O Brasil está ligado, sob o ponto de vista regional, ao Sistema Interamericano de Proteção e Promoção dos Direitos Humanos, organizado pela OEA - Organização dos Estados Americanos, que conta com duas entidades responsáveis pelo seu cumprimento: a Comissão Interamericana de Direitos Humanos e a Corte Interamericana de Direitos Humanos. Foi para onde a família de Damião Ximenes Lopes recorreu.

\footnotetext{
2 TRINDADE, Antônio Augusto Cançado. A proteção internacional dos direitos humanos: fundamentos jurídicos e instrumentos básicos. São Paulo: Saraiva,1991. p.3
}

Revista Brasileira de Direito Internacional, Curitiba, v.3, n.3, jan./jun.2006 
O tema dos direitos humanos sempre foi uma preocupação nas Américas, local onde surgiu o primeiro documento supranacional de direitos humanos: a Declaração Americana de Direitos e Deveres do Homem, cuja promulgação ocorreu em abril de 1948, na mesma ocasião da criação da

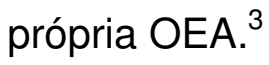

\begin{abstract}
A Declaração Americana difere da Declaração Universal em termos de conteúdo porque não é apenas uma declaração de direitos. Ela estabelece não somente os direitos inerentes a todos os seres humanos, dotados de atributos inatos de dignidade, liberdade e igualdade. Em função dos atributos igualmente congênitos de razão e consciência da pessoa humana, ela estabelece também deveres correlatos a esses direitos.

De acordo com o segundo parágrafo de seu Preâmbulo: "Se os direitos exaltam a liberdade individual, os deveres exprimem a dignidade dessa liberdade". Procura-se assim a adequação do documento à doutrina jurídica tradicional de que a cada direito corresponde um dever. ${ }^{4}$
\end{abstract}

Em 1960 foi aprovada a criação da Comissão Interamericana de Direitos Humanos, que já estava prevista na Resolução III da Quinta Reunião de Consulta de Ministros de Relações Exteriores dos países americanos, realizada no ano anterior (1959). Por essa resolução também foi recomendada ao Conselho Interamericano de Jurisconsultos a elaboração de projetos de criação de uma Convenção de Direitos Humanos e de uma Corte de Proteção dos Direitos Humanos ${ }^{5}$.

O sistema interamericano deixou de ser meramente declaratório e tornou-se mais efetivo com o surgimento, em 1969, da Convenção Americana sobre Direitos Humanos, conhecida como Pacto de São José. Ela estabelece que a Comissão Interamericana de Direitos Humanos e a Corte Interamericana de Direitos Humanos são os órgãos competentes para conhecer os assuntos relacionados com o cumprimento dos compromissos contraídos pelos Estadospartes na Convenção.

\footnotetext{
${ }^{3}$ A Declaração Universal dos Direitos Humanos foi aprovada pela Assembléia Geral da ONU alguns meses depois, em dezembro do mesmo ano.

${ }^{4}$ ALVES, José Augusto Lindgren. A arquitetura internacional dos direitos humanos. Coleção Juristas da Atualidade - coord. Hélio Bicudo. São Paulo: FTD, 1997, p.272

${ }^{5}$ A necessidade do estabelecimento de uma "Corte Interamericana para Proteger os Direitos do Homem já havia sido prevista nas Resoluções XXXI e XXIX da Nona e Décima Conferência Internacional Americana, realizada em Bogotá, Colômbia, em 1948, e Caracas, Venezuela, em 1954, respectivamente.
}

Revista Brasileira de Direito Internacional, Curitiba, v.3, n.3, jan./jun.2006 
No entanto, não houve a imediata criação da Corte e a Comissão atuou em regime de transição até a entrada em vigor da Convenção, o que ocorreu somente em julho de 1978. Então, em 1979 a Assembléia Geral da OEA aprovou o Estatuto da Corte e em 1980 foi aprovado seu regulamento, que vem sendo modificado periodicamente, sendo que a última alteração ocorreu em 1996.

\section{A COMISSÃO INTERAMERICANA DE DIREITOS HUMANOS}

Os familiares da vítima, como apoio de uma Organização Nãogovernamental, encaminharam denúncia à Comissão Interamericana de Direitos Humanos no dia 22 de novembro de 1999, sendo que em 9 de outubro de 2002, ela foi acatada

A Comissão tem como função geral promover a observância e a defesa dos direitos humanos, para o que é composta de sete membros oriundos de distintos países-membros da OEA, considerados de alta autoridade moral e reconhecida atuação em matéria de direitos humanos. Eles são escolhidos pela Assembléia Geral da OEA a partir das listas com até três candidatos propostas pelos Estados Membros, com mandato de quatro anos, sendo permitida uma reeleição. Ela está localizada em Washington.

O art. 29 do Regulamento da Comissão impede seus membros de atuarem em casos em que sejam nacionais do Estado denunciado, estejam acreditados ou cumprindo missão especial como agente diplomático perante tal Estado ou, ainda, se previamente já haviam participado de alguma decisão do caso ou atuado como representantes ou conselheiros das partes interessadas. Esse impedimento não existe na Corte.

A atuação da Comissão decorre basicamente do sistema de petições e comunicações a que está vinculada e que caracteriza os instrumentos de proteção dos direitos humanos. Segundo esse sistema, podem ser apresentadas perante a Comissão petições ou comunicações que contenham denúncias ou queixas de violação, por um Estado-membro da OEA, dos preceitos da Convenção ou da Declaração Americana de Direitos Humanos.

Revista Brasileira de Direito Internacional, Curitiba, v.3, n.3, jan./jun.2006 
Os Estados denunciados que ratificaram a Convenção são processados pela Comissão segundo as normas da Convenção. Já em relação aos Estados denunciados que não ratificaram a Convenção, é aplicada a Declaração.

A distinção entre petições e comunicações está relacionada às partes nelas envolvidas. Assim, qualquer pessoa, ou grupo de pessoas, e ainda as organizações não-governamentais legalmente reconhecidas em um ou mais Estados-membros da OEA possuem legitimidade para interpor petição. ${ }^{6}$

Em relação às comunicações, elas podem ser interpostas por um Estado-membro alegando que outro Estado-membro violou direitos previstos na Convenção. Nesse caso, possuem legitimidade, tanto ativa como passiva, apenas os Estados-membros que declararam perante a Secretaria Geral da OEA seu reconhecimento da competência da Comissão para tratar de comunicações. Essas declarações podem ser feitas por tempo indeterminado ou determinado para casos específicos.

São requisitos para a interposição e admissão da petição ou comunicação:

a) Haver interposto e esgotado todos os recursos de jurisdição interna;

b) Haver apresentado a petição ou comunicação dentro do prazo de seis meses contados da data da notificação da decisão definitiva;

c) Não estar a matéria em questão pendente de outro procedimento de solução internacional de controvérsias.

Esses requisitos não precisam ser preenchidos nos casos em que não exista na legislação interna do Estado envolvido o devido processo legal para a proteção do direito em questão; não foi permitido ao lesionado o acesso aos recursos da jurisdição interna - ou lhe foi impedido seu esgotamento, e, ainda, se houve demora injustificada da decisão de tais recursos.

Uma vez reconhecida a admissibilidade da petição ou comunicação, a Comissão solicita ao Estado denunciado mais informações, com base nas

\footnotetext{
${ }^{6}$ Diferente do Sistema Europeu de Direitos Humanos, no qual apenas a vítima ou seu representante podem peticionar à Comissão.
}

Revista Brasileira de Direito Internacional, Curitiba, v.3, n.3, jan./jun.2006 
quais pode rever seu juízo e declarar a inadmissibilidade do pedido. A partir daí, passa a verificar a existência dos motivos alegados, determinando ou não o arquivamento. Dando continuidade ao procedimento, a Comissão realiza novo exame da matéria e das provas, podendo realizar uma audiência com a presença dos representantes das partes e, ainda, uma investigação in loco do assunto. ${ }^{7}$ Então, ela prepara um informe de caráter privado (somente divulgado aos estados interessados) onde expões os fatos e suas conclusões, ficando a seu critério a formulação de proposições e recomendações.

Após o envio do informe, e se julgar ser a melhor atitude para a prevalência dos Direitos Humanos, a Comissão pode optar por enviar o caso para julgamento na Corte Interamericana de Direitos Humanos, mas desde que o Estado envolvido tenha aceitado a sua jurisdição, seja de forma irrestrita ou específica para o caso em questão.

Como o Brasil havia reconhecido a jurisdição da Corte em 1998, no caso Damião Ximens Lopes a Comissão decidiu enviar a demanda àquele órgão jurisdicional (decisão de 30 de setembro e envio em $1^{\circ}$ de outubro de 2004) com o objetivo de que decidisse se o Brasil era responsável pela violação dos direitos consagrados nos artigos 4 (Direito à Vida), 5 (Direito à Integridade Pessoal), 8 (Garantias Judiciais) e 25 (Proteção Judicial) da Convenção Americana, cumulada com a obrigação de respeitar os direitos, prevista no artigo 1.1. Embora a vítima se encontrasse numa clínica particular, o serviço público de assistência médica a ela prestado fazia parte do Sistema Único de Saúde, do governo brasileiro, que deveria garantir condições dignas de tratamento e internamento.

Retornado à sistemática da Comissão, caso o assunto não seja solucionado ou submetido à decisão da Corte no prazo de três meses, contado a partir do envio do informe da Comissão aos Estados, a Comissão pode, por voto da maioria absoluta de seus membros, emitir sua opinião e conclusões sobre o caso, fixando prazo para a realização das medidas necessárias para o

\footnotetext{
${ }^{7}$ Uma delegação da Comissão realizou visita in loco no Brasil, em diversas regiões do país, durante os meses de novembro e dezembro de 1995, em virtude de alguns casos que se encontravam sob sua análise. Dentre eles, destaca-se o caso 11.405, que denuncia o Brasil em virtude de crimes contra trabalhadores rurais na região de Xinguara e Rio Maria, Estado do Pará.
}

Revista Brasileira de Direito Internacional, Curitiba, v.3, n.3, jan./jun.2006 
cumprimento das suas recomendações. Transcorrido esse novo prazo, a Comissão decide se o Estado tomou ou não as medidas adequadas e se publica ou não seu informe, que é "praticamente um julgamento".

O Estado ou o peticionário pode solicitar, uma única vez, a reconsideração das conclusões ou recomendações do Informe da Comissão, a qual decidirá sobre esse pedido e poderá fixar novo prazo para seu cumprimento. Existem dois requisitos básicos para a solicitação da reconsideração: prazo - 15 dias contados a partir da data do recebimento do informe; e conteúdo - novos fatos ou considerações de direito que não haviam sido anteriormente aludidas.

Durante todo esse procedimento, a qualquer momento, por sua própria iniciativa ou a pedido das partes, a Comissão pode atuar como órgão de solução amistosa da controvérsia, desde que considere essa opção pertinente. Também há previsão da adoção de medidas cautelares para evitar a ocorrência de danos irreparáveis aos seres humanos envolvidos no caso.

Além dessas funções relacionadas ao sistema de petições, a Comissão tem a atribuição de solicitar opiniões consultivas à Corte sobre interpretação da Convenção, comparecer em todos os casos submetidos à Corte, promover a consciência dos direitos humanos em toda a América e, em relação aos Estados-membros, formular-Ihes recomendações, solicitar- Ihes informes e atender as suas consultas e aos pedidos de assessoria.

\footnotetext{
"A Comissão Interamericana, diferentemente de sua similar européia, tem um amplo campo de competência para publicar temas de direitos humanos, através de informes, estudos, palestras e etc:. Ela também pode fazer recomendações aos Estados para adotarem medidas progressivas em favor dos direitos humanos e realizar, com o consentimento do Estado, investigações in loco. Também oferece aos Estados serviços gerais de assessoria na área de direitos humanos e submete seu informe anual à Assembléia Geral da OEA.",
}

\footnotetext{
${ }^{8}$ MELLO, Celso D. de Albuquerque. Curso de Direito Internacional Público. Rio de Janeiro: Renovar, 2000. p.836.

9 "The Comission has, unlike its European counterpart, a wide-ranging competence to publicise human rights matters by way of reports, studies, lectures and so forth. It may also make recommendations to states on the adoption of progressive measures in favour of human rights and conduct onsite investigations with the consent of the state in question. It provides states generally with advisory services in the human rights field and submits an annual report to the OAS General Assembly". SHAW, Malcolm Nathan. International Law. Cambridge: Cambridge University Press, 1997, p.288
}

Revista Brasileira de Direito Internacional, Curitiba, v.3, n.3, jan./jun.2006 
Pode-se concluir, a respeito da Comissão, que ela "não é um tribunal. Por isso mesmo, suas decisões não têm o peso e a força das sentenças judiciais. Mas talvez, seja essa a razão pela qual ela se move e atua com grande flexibilidade, sem esquecer que sua melhor arma é a opinião pública internacional das Américas". ${ }^{10}$

\section{A CORTE INTERAMERICANA DE DIREITOS HUMANOS}

Com sede oficial em São José, Costa Rica, a Corte Interamericana de Direitos Humanos está prevista na Convenção Americana sobre Direitos Humanos, cuja aplicação e interpretação constituem exatamente seu objetivo. Seu Regulamento dispõe sobre as normas de procedimento e seu Estatuto outorga-Ihe as funções jurisdicionais e consultivas.

As funções jurisdicionais se relacionam à adoção de medidas provisionais que a Corte considere como necessárias para casos de danos irreparáveis às pessoas, extrema gravidade e urgência, e à resolução dos conflitos que the são apresentados e que aleguem a violação da Convenção por um dos Estados-partes que declararam o reconhecimento de sua competência. Esta última função é considerada como a "função contenciosa" da Corte. No exercício desta função, sempre que reconhecer a violação de direitos humanos alegada, a Corte tem o dever de garantir ao lesionado o gozo de seu direito ou liberdade tolhidos e de determinar a reparação das conseqüências e o pagamento de uma indenização justa.

Toda emissão de parecer feita a pedido dos Estados-membros e dos órgãos da OEA, constitui-se na função consultiva da Corte. Essas consultas podem versar sobre a interpretação da Convenção ou sobre a interpretação de outros tratados que se refiram aos direitos humanos nos Estados Americanos. Os Estados-membros da OEA também podem solicitar a opinião da Corte sobre e a compatibilidade entre qualquer de suas leis internas e os referidos instrumentos internacionais.

${ }^{10}$ RUSSOMANO, Gilda Maciel Corrêa Meyer. Direitos Humanos. Curitiba: Juruá, 1992, p.45

Revista Brasileira de Direito Internacional, Curitiba, v.3, n.3, jan./jun.2006 
A Corte é composta de sete juízes nacionais de diferentes Estadosmembros da OEA, que devem reunir as condições requeridas para o exercício das mais elevadas funções judiciais conforme a lei do seu país, possuindo, portanto, a mais alta autoridade jurídica moral e reconhecida competência em matéria de direitos humanos. A eleição dos membros é feita nos mesmos moldes da Comissão, mas o mandato é de seis anos.

O juiz conserva seu direito de conhecer o feito mesmo que seja nacional de algum Estado envolvido. Porém, nesse caso, pode haver atuação de juiz ad hoc designado por outro Estado envolvido. Os próprios juízes da Corte podem designar juízes ad hoc quando nenhum deles tiver a nacionalidade dos Estados envolvidos.

Somente têm direito de submeter um caso à decisão da Corte a Comissão e os Estados que reconheceram sua competência obrigatória. Esse reconhecimento pode ser:

- Incondicional ou sob condição de reciprocidade;

- Por prazo indeterminado ou determinado (para casos específicos);

- Declarado no momento do depósito do instrumento de ratificação ou adesão à Convenção ou qualquer momento posterior;

- Obrigatória de pleno direito e sem convenção especial ou por declaração/convenção especial;

A Comissão atua integralmente em todo processo judicial perante a Corte, não existindo participação do indivíduo envolvido, cujo representante legal figura apenas como assistente da Comissão. ${ }^{11}$

Antônio Augusto Cançado Trindade faz uma análise crítica sobre essa inexistência do acesso do homem à Corte, sem precisar da assistência paternalista da Comissão.

\footnotetext{
${ }^{11}$ A única previsão de atuação do indivíduo, ainda que incipiente, aparece somente na reforma do Regulamento da Corte de 1996, vigente a partir de 1\%/01/1997, que, em seu art.23, trata da "Representação das vítimas e seus familiares". Segundo o artigo, "na etapa de reparações, os representantes das vítimas ou de seus familiares poderão apresentar seus próprios argumentos e provas de forma autônoma".
}

Revista Brasileira de Direito Internacional, Curitiba, v.3, n.3, jan./jun.2006 


\begin{abstract}
"Com efeito, reconhecer o locus standi in judicio das vítimas (ou de seus representantes) ante a Corte (em casos já submetidos a esta pela Comissão) contribui à "jurisdicionalização" do mecanismo de proteção (na qual deve recair toda a ênfase), pondo fim à ambigüidade da função da Comissão, a qual não é rigorosamente "parte" no processo, mas antes guardiã da aplicação correta da Convenção. (...) A evolução no sentido da consagração final destas funções distintas deve dar-se pari passu com a gradual jurisdicionalização do mecanismo de proteção. Desta forma se afastam definitivamente as tentações de politização da matéria, que passa a ser tratada exclusivamente à luz de regras do direito. Não há como negar que a proteção jurisdicional é a forma mais evoluída de salvaguarda dos direitos humanos, e que melhor atende aos imperativos do direito e da justiça. ${ }^{12,}$
\end{abstract}

A sentença da corte é motivada, definitiva, inapelável, notificada às partes e transmitida aos Estados partes da Convenção. A parte que trata de indenização compensatória poderá ser executada no respectivo país através do procedimento interno vigente para a execução de sentenças contra o Estado.

No decorrer do processo dos familiares de Damião Ximenes Lopes, a Corte afastou a exceção preliminar apresentada pelo Estado brasileiro de não-esgotamento dos recursos internos. O Brasil fez o reconhecimento de sua responsabilidade internacional pela violação dos artigos 4 e 5 da Convenção Americana.

$\mathrm{Na}$ longa sentença proferida no dia 4 de julho de 2006, a Corte Interamericana, por unanimidade, reconheceu e declarou a responsabilidade internacional do Brasil pela violação dos direitos à vida e à integridade pessoal da vítima (os artigos 4.1 e 5.1 e 5.2 da Convenção Americana) e dos direitos à integridade pessoal (artigo 5) e os direitos às garantias judiciais e à proteção judicial (8.1 e 25.1) de Albertina Viana Lopes, Irene Ximenes Lopes Miranda, Francisco Leopoldino Lopes e Cosme Ximenes Lopes, familiares da vítima.

Da mesma forma, por unanimidade, declarou que o Estado deve garantir a efetividade do processo interno destinado a investigar e sancionar os responsáveis pelos fatos; deve publicar, no prazo de seis meses, o Capítulo VII da sentença da Corte, relativo aos fatos ali provados; deve continuar a desenvolver programa de formação e capacitação para profissionais e pessoas

\footnotetext{
${ }^{12}$ TRINDADE, Antonio Augusto Cançado. Memorial em prol de uma nova mentalidade quanto à proteção dos direitos humanos nos planos internacional e nacional. Carlos Eduardo de Abreu Boucault e Nádia de Araújo (Orgs.). Os direitos humanos e o direito internacional. Rio de Janeiro: Renovar, 1999. p. 15 e 18.
}

Revista Brasileira de Direito Internacional, Curitiba, v.3, n.3, jan./jun.2006 
envolvidas com atendimento de saúde mental, sobretudo quanto aos princípios que devem reger esse trabalho, conforme os padrões internacionais; deve pagar no prazo de um ano, em dinheiro, indenização por dano material, dano imaterial e custas processuais, nas quantias fixadas na própria sentença, para os familiares da vítima.

Por fim, a Corte confirmou que vai fazer a supervisão do cumprimento da sentença devendo o Estado apresentar-lhe relatório sobre as medidas adotadas para tanto.

Até a expedição dessa sentença pela Corte, sendo a primeira relacionada ao Brasil, a análise dos casos envolvendo o país se limitava às denúncias na Comissão Interamericana de Direitos Humanos. Nelas, em geral os casos envolvem policiais militares ou questões agrárias. Na maioria das vezes o país se defende alegando que não houve esgotamento dos recursos internos disponíveis para solucionar os conflitos. Em muitos casos, o Governo brasileiro simplesmente não respondeu aos questionamentos da Comissão, o que sempre ocorreu com a proposta de utilização do mecanismo de solução amigável para o conflito.

A presente decisão demonstra um certo avanço do posicionamento do Brasil, embora muito ainda precise ser feito. O próprio reconhecimento da jurisdição da Corte já é positivo, ainda que tardio. As alegações preliminares, sobretudo quanto ao esgotamento dos recursos internos, são mantidas, mostrando uma certa reticência no progresso. Entretanto, o reconhecimento da violação dos direitos à vida e integridade física pelo Estado brasileiro pode ser indício de um futuro posicionamento mais consciente do país em relação aos demais casos a serem analisados pela Corte Interamericana. Melhor ainda seria resolver os casos já na Comissão sem precisar chegar à Corte, sendo que o ideal mesmo seria não promover ou não se omitir na violação dos direitos humanos dentro do território nacional, de modo que o recurso à jurisdição internacional nem se fizesse necessário.

Nessa linha de pensamento, Flávia Piovesan assevera: "Embora avanços extremamente significativos tenham ocorrido ao longo do processo de democratização brasileira, no que tange à incorporação de mecanismos 
internacionais de direitos humanos, ainda resta o importante desafio - quase que decisivo ao futuro democrático - do pleno e total comprometimento do Estado brasileiro à causa dos direitos humanos".13

É o comprometimento que os brasileiros esperam de seu país.

\section{REFERÊNCIAS}

ALVES, José Augusto Lindgren. A Arquitetura Internacional dos Direito Humanos. Coleção Juristas da Atualidade (Coordenação Hélio Bicudo). SãoPaulo: FTD, 1997.

ALVES, José Augusto Lindgren. Os direitos humanos como tema global. São Paulo: Perspectiva e Fundação Alexandre de Gusmão,1994.

BOUCAULT, Carlos Eduardo de Abreu, ARAÚJO, Nádia (Orgs.) Os direitos humanos e o direito internacional. Rio de Janeiro: Renovar, 1999.

LEITE, Eduardo de Oliveira. A Monografia Jurídica. 4 ed. São Paulo: Revista dos Tribunais, 1999.

MELLO, Celso D. de Albuquerque. Curso de Direito Internacional Público. Rio de Janeiro: Renovar, 2v.

PIOVESAN, Flávia. Direitos Humanos e o Direito Constitucional Internacional. São Paulo: Max Limonad, 1997.

RUSSOMANO, Gilda Maciel Corrêa Meyer. Direitos Humanos. Curitiba: Juruá, 1992.

SHAW, Malcon M. International Law. Cambridge: Cambridge University Press, 4th edition, 1997.

TRINDADE, Antônio Augusto Cançado. A proteção internacional dos direitos humanos: fundamentos jurídicos e instrumentos básicos. São Paulo: Saraiva, 1991.

TRINDADE, Antônio Augusto Cançado. (Ed.). A incorporação das normas internacionais de proteção dos direitos humanos no direito brasileiro. San José da Costa Rica: IIDH, ACNUR, CICV, CUE. 1996.

\footnotetext{
${ }^{13}$ PIOVESAN, Flávia. Direitos Humanos e o Direito Constitucional Internacional. São Paulo: Max Limonad, 1997. 3 ed. p.330.
}

Revista Brasileira de Direito Internacional, Curitiba, v.3, n.3, jan./jun.2006 